\title{
Maternal Obesity, Metabolic Health, and Prenatal Programming of Offspring Obesity
}

\author{
Paula C. Chandler-Laney ${ }^{*}$ and Nikki C. Bush \\ Department of Nutrition Sciences, University of Alabama at Birmingham, Birmingham, AL 35294, USA
}

\begin{abstract}
Children born to overweight and obese women, as compared to those of normal weight women, have greater risk for becoming obese themselves and suffering comorbid metabolic health problems. Evidence is accumulating that this increased susceptibility is at least partially attributed to a prenatal programming effect, whereby obesogenic factors in the intrauterine environment alter fetal development of systems involved in body weight regulation thereby promoting deposition of excess adipose tissue. There is little evidence that maternal adipose tissue in and of itself is involved in programming the developing fetus toward obesity; rather, maternal obesity increases risk for metabolic health perturbations during pregnancy and it is these perturbations that appear to be involved in programming offspring risk for obesity. The considerable variability in the metabolic health of individuals, even among those of the same body mass index (BMI), highlights the fact that maternal BMI lacks precision for the identification of pregnancies that will convey increased risk of obesity to offspring. The purpose of the following review is to discuss evidence that maternal metabolic health is involved in the prenatal programming of obesity, and to identify simple maternal markers related to metabolic health, that may increase precision in the identification of obesogenic pregnancies.
\end{abstract}

Keywords: BMI, adiposity, metabolic health, gestational diabetes, hypertension, inflammation, dyslipidemia, waist circumference, family history, recent weight gain.

\section{INTRODUCTION}

Rates of childhood obesity in the United States continue to rise despite increased public health awareness. National Health and Nutrition Examination Survey (NHANES) data collected in 2003-4 found that the prevalence of overweight and at risk for overweight was $26 \%$ among children aged 2-5 year and $37 \%$ among children aged 6-11 years; representing a $20-25 \%$ increase in prevalence since 1999 [1]. Given the relative ineffectiveness of weight loss and weight loss maintenance interventions, the best "treatment" for obesity is likely to be primary prevention. In recent years, strong evidence in support of prenatal programming of offspring obesity has accrued, whereby factors related to maternal health are believed to alter fetal development in utero in a manner that promotes excess adipose tissue deposition during pre- or post-natal life. Thus, the optimal time to prevent childhood obesity may be during pregnancy itself. But, how do we pre-determine which children may benefit from an intervention provided to mothers during pregnancy? Certainly, evidence suggests that children of women who begin pregnancy in an overweight or obese state are at greater risk for becoming obese themselves, but there is little evidence that maternal adipose tissue itself directly contributes to the prenatal programming of obesity. Rather, excess adiposity among women increases the risk for other metabolic health abnormalities during pregnancy, and it is those abnormalities that appear more likely to contribute to

*Address correspondence to this author at the Department of Nutrition Sciences, 1675 University Blvd., WEBB 413, Birmingham, AL 352943361, USA; Tel: 205.934.0809; Fax: 205.934.7049; E-mail: pchandle@uab.edu offspring obesity risk. But considerable variability exists in terms of metabolic health among people of any given weight. Therefore, maternal weight lacks precision as an identifier of risk for providing an obesogenic intrauterine environment to offspring.

The purpose of this review is to examine what is known about associations between maternal BMI status and metabolic health abnormalities, and their potential effect on prenatal programming of obesity among offspring. We will briefly review the literature regarding associations between maternal and offspring obesity, then discuss evidence for the involvement of maternal obesity-related metabolic abnormalities in the prenatal programming of obesity. Finally, we will discuss potential identifiers of pregnancies that carry increased risk for providing an obesogenic environment. Although many other reviews have been written regarding the consequences of maternal obesity during pregnancy, to our knowledge, none has focused on the topic of refining the identification of pregnancies that are likely to convey increased obesity risk to offspring. This discussion is not intended to be an exhaustive review of the literature, but rather aims to stimulate thought regarding how we might achieve the earliest and most precise identification of children who are at risk for prenatal programming of obesity, at a time when prevention may be possible.

\section{ASSOCIATIONS BETWEEN MATERNAL OBESITY AND OFFSPRING RISK FOR OBESITY}

Numerous studies have shown a relationship between exposure to maternal obesity in utero and offspring obesity at various ages. In a meta-analysis of published studies, Chu et al. [2] found that the prevalence of macrosomia among 
neonates of obese women was almost double that of those born to women of normal weight. Although across a range of birth weights, increased birth weight is not associated with increased adiposity [3], those at the extreme upper end of birth weights have greater fat mass than those born of appropriate size for gestational age [4, 5]. Beyond birth, infants and children born to women who were overweight prior to or early in pregnancy have greater BMI and more adiposity than children born to women of normal weight [612]. Finally, children born to overweight women have increased risk of indices associated with metabolic syndrome such as insulin resistance and dyslipidemia [7, 13, 14]. Although these studies are observational and as such, cannot imply causation, the consistency of these findings lends credence to the hypothesis that intrauterine exposure to maternal obesity predisposes offspring toward the development of obesity and impaired metabolic health.

Studies investigating modifications in maternal weight prior to conception have provided more support for a causal relationship between maternal and offspring birth weight or obesity. In consecutive pregnancies, women with increases in pre-pregnancy BMI from normal to obese between the first and second pregnancies had significantly increased risk for delivering a large-for-gestational-age (LGA) neonate, whereas in women with a decrease in pre-pregnancy BMI, risk of LGA was attenuated compared to those who maintained a higher BMI in the second pregnancy [15]. In a study of children born prior to or after their mothers' weight loss surgery, Kral et al. [16] showed that the prevalence of obesity among children born post surgery was similar to that of the general population $(\sim 35 \%)$, whereas the prevalence among children born prior to mothers' weight loss surgery was significantly greater $(60 \%)$. Interestingly, this effect was observed despite the fact that the mothers were matched for BMI at the time of conception, suggesting that a mechanism other than that related to absolute amount of maternal adiposity increases risk of obesity among offspring. A comparable effect has been shown among Pima Indians who have a very high prevalence of type 2 diabetes, wherein children born prior to a maternal diagnosis of type 2 diabetes were less likely to become obese and diabetic themselves as compared to their siblings who were born following the development of maternal diabetes [17]. Data from animal models also support a causal effect of maternal obesity on offspring adiposity [18-20]. In an interesting study of offspring from obesity-prone dams who were permitted to become obese versus those who remained lean, pups from obese dams had greater adiposity than pups from the lean but obesity-prone dams [18]. These data suggest that despite a similar genotypic predisposition for obesity, differences in the intrauterine environment explain variance in offspring presentation of obesity.

The mechanisms underlying the interrelationships between maternal obesity and offspring adiposity and metabolic health are yet to be clearly elucidated. There is little evidence that the observed association between maternal and offspring obesity is due to excess maternal adiposity itself. Rather, a significant portion of the risk to offspring of women who were overweight during pregnancy is believed to be attributable to the influence of obesity-induced abnormalities in maternal metabolic health on prenatal programming of fetal body composition and metabolism.

\section{MATERNAL METABOLIC FACTORS RELATED TO PRENATAL PROGRAMMING OF OBESITY}

The hypothesis that the prenatal environment predisposes individuals to certain phenotypes [21, 22] has been gaining support in recent years. Pertinent to this review, obesity in the mother is hypothesized to alter her metabolism in a manner that supports an "obesogenic" intrauterine environment; providing excess nutrient supply to the developing fetus, and thereby programming altered fetal metabolism that promotes adipose tissue deposition [23, 24]. Although evidence supporting this hypothesis has accumulated, the obesity-induced changes in maternal metabolism that impact fetal development have not been fully elucidated.

Excess adiposity is commonly associated with abnormal metabolic health such as impaired glucose tolerance, dyslipidemia, hypertension and inflammation. Among nonpregnant adults, clustering of these symptoms determines the presence of the metabolic syndrome and is predictive of future cardiovascular disease and type 2 diabetes. A study from Ramsay et al. [25] showed that these metabolic perturbations are more common among obese versus lean pregnant women, and are sustained throughout pregnancy. Furthermore, due to the increased metabolic demands of pregnancy, subtle deficits in metabolic health may initially only be identified during pregnancy and resolved following pregnancy, at least until such time as other factors such as age or adiposity facilitate progression to a clinically recognized disorder. Indeed, studies have shown that women with a history of gestational diabetes and hypertensive disorders during pregnancy are more likely to develop components of metabolic syndrome in later life [26-29]. Consequently, metabolic abnormalities presenting during pregnancy may be indicative of subtle underlying impairments in women that not only predict her future health, but also, as discussed below, may directly influence obesity risk in offspring.

\section{Impaired Glucose Tolerance}

By far, the greatest amount of research regarding maternal metabolic health and offspring obesity has centered on the effect of impaired maternal glucose tolerance. Maternal insulin resistance serves a functional purpose during pregnancy in that it increases delivery of glucose to the fetus, facilitating fetal growth. Among healthy women, greater insulin release will counteract this insulin resistance so that maternal glucose concentrations remain within a tight range. If, however, the compensatory insulin response is not sufficient, maternal glucose concentrations will be relatively high and fetal overgrowth may occur. Women who are overweight and obese prior to, or early in, pregnancy are more likely to have reduced insulin sensitivity [24] and insufficient compensation for that reduced sensitivity, resulting in gestational diabetes [2, 30]. Furthermore, although impaired glucose tolerance is more likely to occur in women who are overweight or obese, any subtle deficits of glucose metabolism among women of normal weight may initially present themselves during pregnancy because of changes in metabolic demands.

The effect of gestational diabetes on offspring obesity has been extensively studied. In the 1950's, Pedersen's observation that infants of diabetic mothers were heavier 
than those of non-diabetic controls led him to hypothesize that maternal hyperglycemia among diabetic women resulted in fetal hyperinsulinemia which, in turn, was associated with greater deposition of fat [22]. More recent research has supported this hypothesis by showing that infants born to women with pre-existing or gestational diabetes are larger $[31,32]$ and have greater adiposity at birth [33]. It is now apparent that even mild, subclinical, elevations in maternal glucose are associated with increased neonatal birth weight and adiposity [34-36]. Beyond birth, children born to women with gestational diabetes continue to be at greater risk for obesity and comorbid metabolic health problems [7, 32, 3740]. Thus, intrauterine exposure to relatively high levels of maternal glucose, which is more likely to occur among children of obese women, increases the risk for excess adipose deposition both during prenatal development and during childhood.

Although the mechanism underlying maternal diabetesrelated prenatal programming of offspring obesity has not been definitively shown, it is believed to be consistent with Pedersen's hypothesis and is outlined in Fig. (1). Elevated insulin and c-peptide (indicative of increased insulin secretion) concentrations have been found in amniotic fluid and cord blood of fetuses of women with gestational diabetes $[36,41,42]$. Regardless of whether the fetal hyperinsulinemia is due to insulin resistance or increased insulin secretion, the insulin is believed to facilitate deposition of excess adipose tissue. Fetal insulin has been associated with subsequent adiposity in childhood and beyond [31, 43]. In addition to the potential for altered programming of the fetal pancreas during development, excess insulin may also affect programming of the hypothalamus, thereby influencing the regulation of satiety and energy balance (for review see [44, 45]). Therefore, intrauterine exposure to elevated maternal glucose is hypothesized to increase fetal insulin concentrations, which in turn may alter prenatal programming of multiple systems important for body weight regulation.

Although obesity and increased maternal glucose concentrations adversely modify offspring risk for obesity, the risk can be attenuated with appropriate intervention. Adequate treatment of gestational diabetes, or even of mild hyperglycemia, has been shown to reduce birth weight and attenuate the risk for obesity among offspring [46-49]. This raises the tantalizing possibility that prenatal programming of obesity by maternal hyperglycemia is modifiable with an appropriate intervention to facilitate maternal glycemic control. Importantly however, it is essential that high-risk pregnancies be identified, even if they don't meet the clinical cut-points for diabetes, in order to appropriately target intervention efforts.

We must also acknowledge that even with successful intervention aimed to achieve optimal control of maternal gestational glucose concentrations, prenatal programming of obesity may still occur. A number of studies have shown an effect of maternal obesity on offspring birth weight and adiposity that is independent of maternal diabetes status [5052]. Although some of this risk may be attributed to an effect

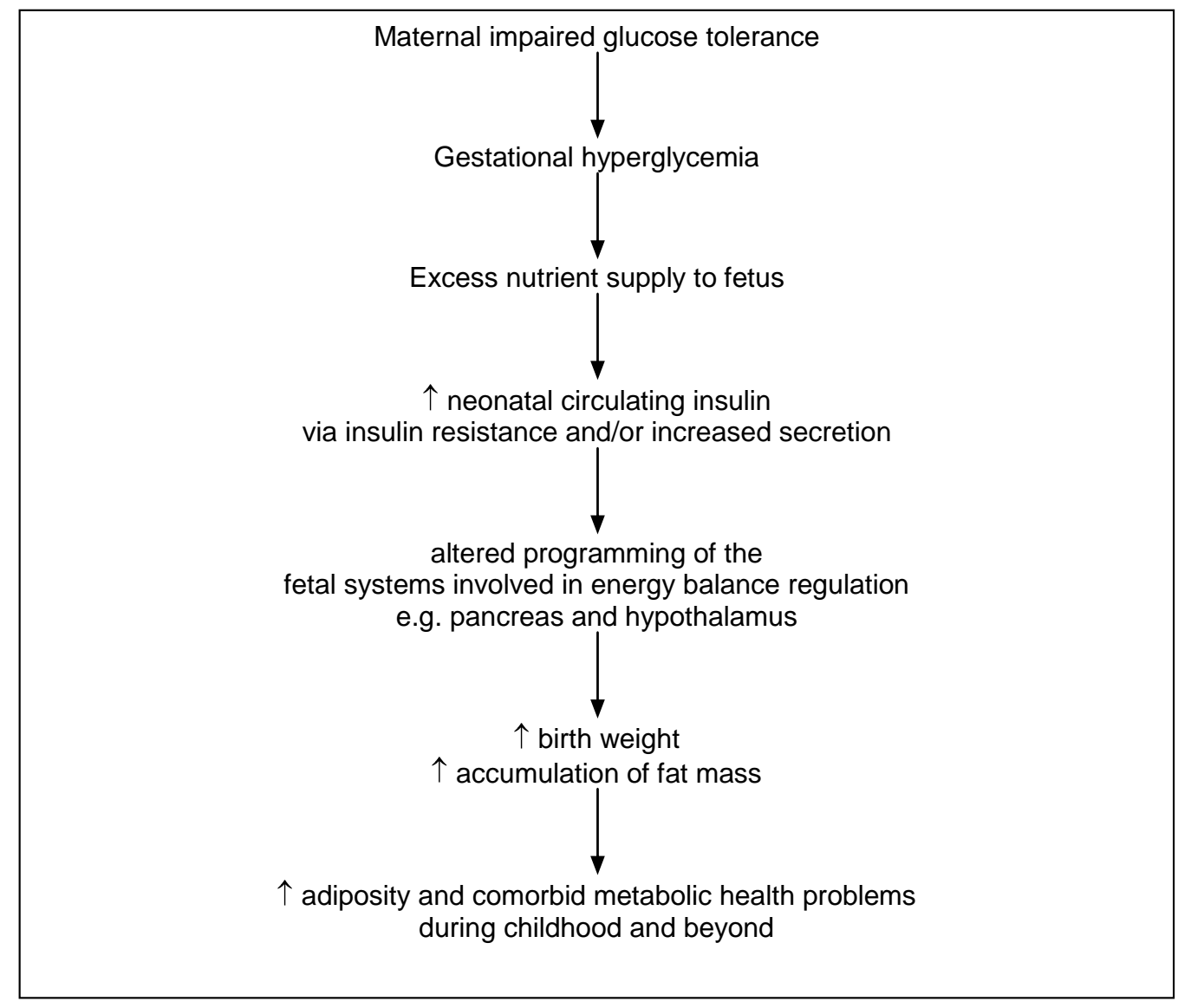

Fig. (1). Hypothesized role for maternal impaired glucose tolerance in the prenatal programming of fetal systems involved in the regulation of energy balance; ultimately predisposing offspring toward the development of obesity. 
of subclinical elevations in maternal glucose among nondiabetic obese women, it is possible that other obesityinduced abnormalities in metabolic health, such as hypertension, hyperlipidemia, and inflammation, also play a role in prenatal programming.

\section{Hypertensive Disorders of Pregnancy}

Pre-pregnancy overweight and obesity is associated with increased systolic and diastolic blood pressure during each trimester of pregnancy compared to that of lean women [53]. It is not surprising therefore, that pregnancy-induced hypertension and preeclampsia are more prevalent among women who are overweight or obese prior to or during pregnancy [54-56]. Hypertension during pregnancy has consistently been related to fetal intrauterine growth restriction (IUGR) presumably due to compromised nutrient delivery to the fetus, and IUGR itself places children at risk for subsequent obesity due to excess adipose deposition during a period of catch-up growth. At the other end of the spectrum however, only a few studies have shown an effect of pregnancy hypertensive disorders on fetal overgrowth and the prevalence of delivering an LGA infant $[57,58]$. While one study showed that this effect was maintained after adjustment for maternal BMI [57], the other did not [58]. Therefore, it is unclear whether hypertensive disorders of pregnancy, in and of themselves, contribute to the prenatal programming of obesity. If a role for maternal hypertension in prenatal programming of obesity exists, a potential mechanism by which this might occur has not been elucidated.

\section{Maternal Lipid Concentrations}

Total cholesterol, high-density lipoprotein - cholesterol (HDL-C), and triglyceride levels increase in normal pregnancy as compared to those of non-pregnant women [59-61]. In comparison to lean pregnant women, obese pregnant women have higher triglyceride and lower HDL-C concentrations [25]. Elevated cholesterol and triglycerides either prior to or during pregnancy are associated with increased risk of complications during pregnancy such as preeclampsia [55], glucose intolerance and gestational diabetes [60, 62, 63]. In terms of offspring outcomes, high maternal triglyceride concentration during pregnancy is associated with increased birth weight, independently of maternal BMI [61-65]. In a study of women with wellcontrolled gestational diabetes, maternal free fatty acids (FFA) and triglyceride concentrations were positively associated with fetal abdominal circumference during the $3^{\text {rd }}$ trimester, and those measured close to delivery were positively associated with levels measured in cord blood and with risk of delivering an LGA infant [65]. Furthermore, elevated maternal triglyceride concentration among this group of women was associated with increased neonatal fat mass. To our knowledge, no other study has shown an association between maternal triglyceride or lipid concentrations during gestation and subsequent childhood adiposity among offspring.

While maternal triglyceride does not cross the placenta, the presence of high triglyceride concentrations during late gestation provides a source for FFA, which are essential for fetal growth. Therefore, a mechanism exists whereby maternal lipids could impact fetal growth and potentially predispose offspring to obesity. More research is needed however, to understand whether perturbations of maternal lipids contribute to increased adiposity in childhood or beyond, and whether the effect of exposure to elevated maternal triglycerides and FFA on neonatal birth weight and adiposity is independent of any other disorders of maternal metabolic health.

\section{Maternal Inflammation}

Obesity has been described as a subclinical inflammatory condition due to the elevated levels of C-reactive protein (CRP) and interleukin-6 (IL-6) found in overweight and obese adults and children $[66,67]$. Increased concentrations of inflammatory markers are associated with future risk for adverse cardiovascular events [68] and for the development of type 2 diabetes [69]. Given these results of general population studies, it is not surprising that women who are obese prior to or early in pregnancy have increased CRP and IL-6 concentrations [25, 70, 71]. Furthermore, maternal CRP is associated with adverse pregnancy-related problems such as preeclampsia [72], and gestational diabetes [71, 73]. In terms of offspring outcomes, one study using an animal model found that offspring of dams administered exogenous IL-6 during pregnancy had more adipose tissue and that male offspring specifically, were more insulin resistant than those from dams not given exogenous IL-6 [74]. To our knowledge, only one clinical study has shown an association between maternal inflammation and offspring obesity, with neonatal adiposity being positively associated with maternal IL-6 concentration [75].

Investigations of placental transfer of IL-6 and other inflammatory cytokines have yielded conflicting results [76, 77], so the potential for maternal inflammation to directly influence offspring birth weight or adiposity is unclear. There is evidence, however, that offspring of obese women have increased inflammation themselves. In a comparison of lean versus obese mothers, Catalano et al. [78] showed that fetal cord blood of neonates born to obese women had higher levels of IL-6 than did that of neonates born to lean mothers, although it was not clear whether this association was related to the increased size of the neonates born to obese women. A study of neonates born to women with type 1 diabetes found that although birth weight was unrelated to IL-6 and CRP concentrations in cord blood, leptin, which corresponds to fetal adiposity, was positively associated with cord blood IL6 and CRP [79]. Thus, while data from clinical studies does not, at this time, support a direct association between the intrauterine exposure to maternal inflammation and fetal overgrowth or prenatal programming of obesity risk, offspring themselves may be at increased risk for being born in a subclinical inflammatory state if they have more adiposity at birth.

Taken together, research indicates that metabolic health abnormalities, rather than frank obesity per se, may explain the increased risk for obesity among children of overweight and obese women. Evidence supports the potential for maternal hyperglycemia due to glucose intolerance, and possibly high maternal triglyceride and FFA concentrations, to directly impact fetal growth and prenatal programming of obesity. Despite the lack of evidence for a direct effect of maternal hypertension or inflammation on offspring adipo- 
sity, their association with other metabolic abnormalities, such as diabetes [71, 73, 80-83], may render them useful indices for the identification of pregnancies that are more likely to provide an obesogenic intrauterine environment. Although we limited our discussion above to maternal indices associated with the metabolic syndrome, there are likely other maternal metabolic perturbations, such as increased glucocorticoid concentrations [84], that are associated with increased adiposity among offspring. More research is needed to characterize all metabolic abnormalities associated with excess adiposity during pregnancy, and to understand potential mechanisms whereby any abnormalities could influence fetal development. Furthermore, given the unique metabolic challenge pregnancy provides, the diseaserisk cut-points that are appropriate for the non-pregnant population may not be applicable for the determination of offspring obesity risk. It is important to work toward developing cut-points specific to pregnancy that portray increased risk for adiposity among offspring.

\section{HOW CAN WE IMPROVE THE IDENTIFICATION OF PREGNANCIES WITH INCREASED RISK FOR PRENATAL PROGRAMMING OF OBESITY?}

One of the underlying assumptions of the hypothesis relating maternal obesity to prenatal programming of obesity is that excess adiposity adversely affects metabolism in the mother. Certainly obesity increases risk for impaired metabolic health, but considerable heterogeneity among obese people exists in terms of the presence and severity of related components related. While two people could share a common BMI, irrespective of whether it is in the lean or obese range, one might present with impairments in metabolic health while the other may not. These differences in metabolic health could potentially result in different prenatal environments, which ultimately may contribute to differences in offspring obesity risk (Fig. 2). The complexity of variation in metabolic health at any given weight class among the non-pregnant population was first acknowledged in the 1980's [85-87], and has recently been reviewed [8891]. The implied message from these studies is that weight status is merely one component associated with metabolic health, but does not identify the actual presence of any metabolic abnormalities.

Similarly, given the data described above regarding the effects of various metabolic health abnormalities on offspring risk for obesity, it is our contention that maternal BMI during early pregnancy is not specific enough to adequately identify pregnancies that are likely to provide an obesogenic intrauterine environment. Among the nonpregnant population, it is estimated that approximately 12$20 \%$ of overweight and obese people lack any components

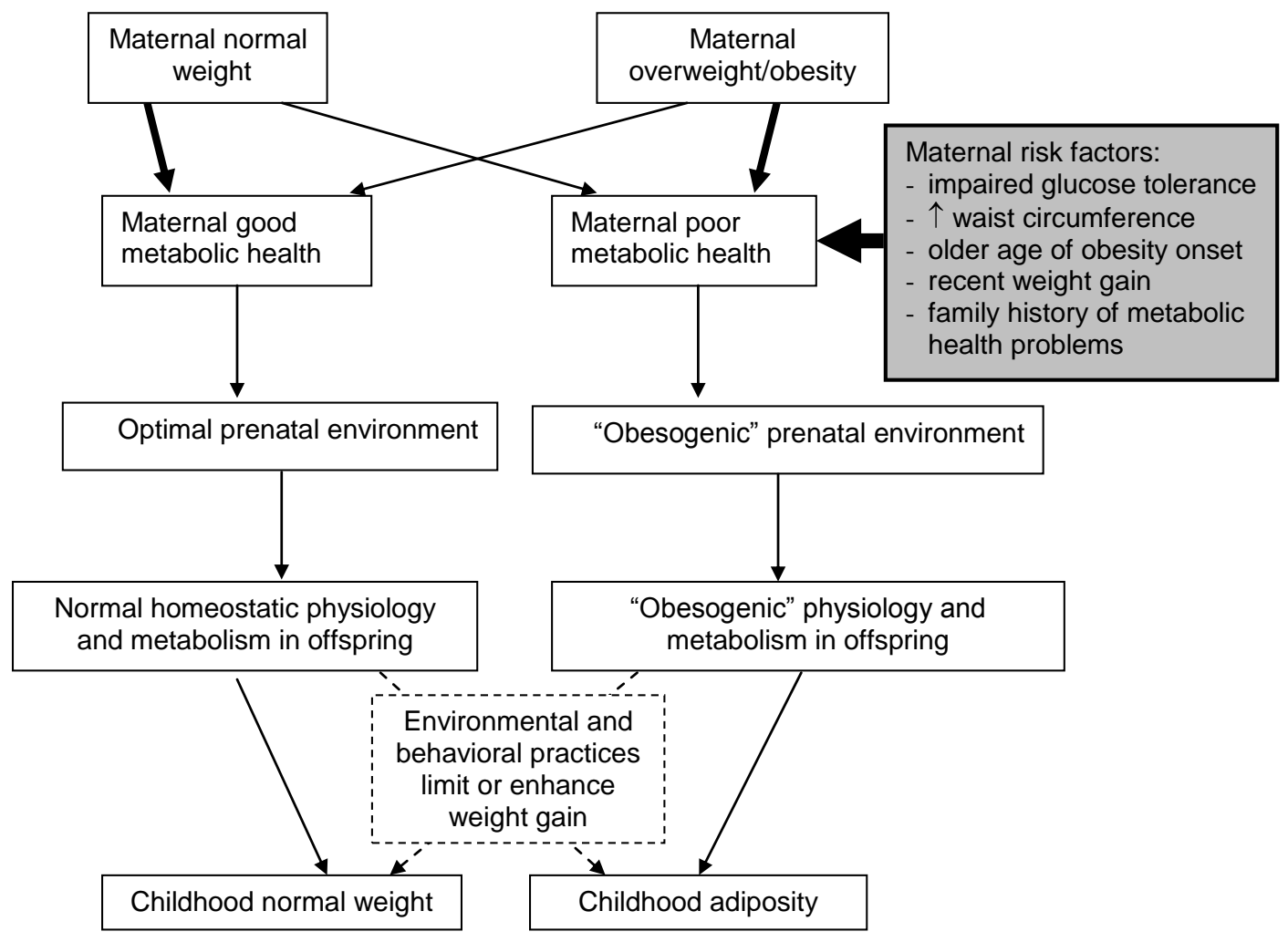

Fig. (2). Hypothesized associations between maternal weight status, maternal metabolic health, and offspring risk for obesity. There is more evidence that perturbations of maternal metabolic health, rather than maternal obesity per se, are directly associated with prenatal programming of obesity. The considerable variability in metabolic health among women of any specific weight however, implies that maternal weight status itself lacks precision for the identification of high risk pregnancies. The gray box denotes maternal markers, independent of simple BMI status, that may be associated with perturbations of maternal metabolic health and thus more likely to dentify pregnancies with higher risk for providing an obesogenic intrauterine environment for offspring. Dashed arrows and box denote potential mediators of the relationship between prenatal programming of obesity and subsequent childhood obesity that are not addressed in this review. 
of the metabolic syndrome [89, 92]. A comparable portion of women who enter pregnancy in an overweight or obese state may be otherwise metabolically healthy and thus pose no greater risk for providing an obesogenic environment to their fetuses than do women who are normal weight early in pregnancy. Conversely, a significant proportion of people with $\mathrm{BMI}$ in the normal range are likely to have one or more components of the metabolic syndrome, potentially placing their children at risk for subsequent obesity. If assessment of offspring risk for obesity were based solely on maternal BMI status, normal weight women with subtle metabolic abnormalities would be overlooked. Research is needed to determine whether women who are obese but otherwise free of any metabolic abnormalities convey any increased risk for obesity, in utero, to their offspring, and comparatively, whether women of normal weight who present with subtle underlying metabolic abnormalities increase the risk of obesity among their offspring. Furthermore, we need to identify reliable markers that are easily obtained in a clinical setting, in addition to weight status, that infer the potential for impaired maternal metabolic health during pregnancy and subsequent risk of offspring obesity.

To address this last point, Sims [90] suggested diagnostic criteria that are associated with metabolic health among obese non-pregnant people. Specifically, despite being overweight or obese, people who might be protected from obesity-related metabolic perturbations are those with normal insulin resistance, those with widely dispersed adiposity (as opposed to a greater proportion of central adiposity), and those who have family members with earlyonset obesity who are relatively free of components associated with the metabolic syndrome. Furthermore, Muscelli et al. [93] and Brochu et al. [94] found that obese people were less likely to be afflicted with components of the metabolic syndrome if they had been obese for a relatively long duration, or if the age of obesity onset was younger than 20 years of age. It is not known whether individuals with relatively early onset obesity are fully protected from impairments of metabolic health, or whether they have a different threshold for mediating factors such as age or adiposity, beyond which metabolic perturbations arise.

Some studies have shown the capacity of these indices to predict maternal metabolic health abnormalities during pregnancy. Specifically, increased maternal waist circumference during early pregnancy, which serves as a proxy index of visceral adiposity [95], has been associated with increased risk for the development of gestational hypertension and preeclampsia [96], and with gestational glucose intolerance [97]. Relatively higher fasting and $2 \mathrm{hr}$ insulin response during an oral glucose challenge prior to 16 weeks gestation is predictive of increased risk for gestational diabetes among women with at least one other risk factor, such as obesity [98]. A family history of preeclampsia or diabetes has been associated with increased risk for preeclampsia and gestational diabetes, respectively [99-101]. Interestingly, there is some evidence that a history of diabetes among maternal relatives conveys greater risk for gestational diabetes than does a similar history among paternal relatives [101]. Hence, prenatal programming of obesity and diabetes risk may well be a self-promoting cycle whereby impaired glucose tole- rance is passed from mother to daughter across multiple generations unless an effective intervention is applied.

Recency of weight gain may also prove efficacious as a predictor of metabolic abnormalities during pregnancy because inter-pregnancy weight gain has been associated with greater risk for gestational diabetes in the second pregnancy $[102,103]$. In the latter study, increased weight gain between pregnancies was also shown to increase risk for preeclampsia and gestational hypertension, and was found even among women who did not become overweight with their inter-pregnancy weight gain. Little research has investigated the association of these simple maternal markers early in pregnancy on subsequent offspring adiposity, although a family history of diabetes and recent maternal weight gain has been associated with increased risk of delivering an LGA infant $[15,103,104]$. Together then, these results suggest that estimates of central adiposity and insulin resistance, and knowledge of recency of obesity onset and family history of obesity and obesity-related metabolic disorders, might improve our ability to identify women, early in pregnancy, who have increased risk for metabolic health impairments during later pregnancy, and subsequently, increased risk for offspring adiposity. Longitudinal studies are needed to investigate the association between these easily obtainable clinical indices and offspring risk for obesity.

To conclude, research to date consistently suggests a role for maternal obesity-related metabolic health abnormalities, rather than maternal adiposity per se, on offspring risk for obesity. The fact that some of these studies show effects on adiposity at birth implies that maternal metabolic health, particularly glucose intolerance, is likely to be involved in prenatal programming of obesity among neonates, and therefore, the optimal time to intervene in order to prevent gain of excess adiposity may be during pregnancy itself. Although such an intervention is unlikely to eliminate childhood obesity altogether due to the role of other postnatal environmental and lifestyle factors in adiposity accrual, an intervention during pregnancy may avoid conveying a predisposition toward obesity for some children who would otherwise be at increased risk due to intrauterine exposure to obesogenic factors. It is beyond the scope of this review article to examine potential interventions, but one designed to facilitate optimal maternal glucose control appears to have the most potential for success given what is known about potential mechanisms underlying prenatal programming of offspring obesity. Simple predictors of adverse maternal metabolic health collected early in pregnancy, such as waist circumference, recency of weight gain, and family history, may prove to be more specific markers of increased risk to offspring than weight status per se. Longitudinal studies are needed to investigate associations between these maternal markers and metabolic health during pregnancy, and subsequent long-term risk for obesity and impaired metabolic health among offspring. While such studies will be costly, improved precision in the identification of pregnancies conveying high risk for obesity to offspring may ultimately reduce healthcare costs associated with the childhood obesity epidemic. Furthermore, more precise identification of highrisk pregnancies will facilitate the development of a targeted intervention that could ultimately break the cycle of intergenerational transmission of obesity within families. 


\section{ABBREVIATIONS}

$$
\begin{aligned}
& \text { BMI }=\text { Body mass index } \\
& \text { LGA }=\text { Large-for-gestational-age } \\
& \text { IUGR }=\text { Intrauterine growth restriction } \\
& \text { HDL-C }=\text { High-density lipoprotein - cholesterol } \\
& \text { FFA }=\text { Free fatty acids } \\
& \text { IL-6 }=\text { Interleukin-6 } \\
& \text { CRP }=\text { C-Reactive protein }
\end{aligned}
$$

\section{REFERENCES}

[1] Ogden CL, Carroll MD, Curtin LR, McDowell MA, Tabak CJ, Flegal KM. Prevalence of overweight and obesity in the United States, 1999-2004. JAMA 2006; 295(13): 1549-55.

[2] Chu SY, Callaghan WM, Kim SY, et al. Maternal obesity and risk of gestational diabetes mellitus. Diabetes Care 2007; 30(8): 2070-6.

[3] Butte NF, Ellis KJ, Wong WW, Hopkinson JM, Smith EO. Composition of gestational weight gain impacts maternal fat retention and infant birth weight. Am J Obstet Gynecol 2003; 189(5): 1423-32.

[4] Hammami M, Walters JC, Hockman EM, Koo WW. Disproportionate alterations in body composition of large for gestational age neonates. J Pediatr 2001; 138(6): 817-21.

[5] Sun M, Schutz Y, Grezzani A, Clementi M, Gaudino R, Maffeis C. Body size and early growth in appropriate- and large-forgestational-age infants. Acta Paediatr 2003; 92(10): 1127-32.

[6] Whitaker RC. Predicting preschooler obesity at birth: the role of maternal obesity in early pregnancy. Pediatrics 2004; 114(1): e2936 .

[7] Boney CM, Verma A, Tucker R, Vohr BR. Metabolic syndrome in childhood: association with birth weight, maternal obesity, and gestational diabetes mellitus. Pediatrics 2005; 115(3): e290-6.

[8] Harvey NC, Poole JR, Javaid MK, et al. Parental determinants of neonatal body composition. J Clin Endocrinol Metab 2007; 92(2): 523-6.

[9] Sewell MF, Huston-Presley L, Super DM, Catalano P. Increased neonatal fat mass, not lean body mass, is associated with maternal obesity. Am J Obstet Gynecol 2006; 195(4): 1100-3.

[10] Hull HR, Dinger MK, Knehans AW, Thompson DM, Fields DA. Impact of maternal body mass index on neonate birthweight and body composition. Am J Obstet Gynecol 2008; 198(4): 416.e1-6.

[11] Burdette HL, Whitaker RC, Hall WC, Daniels SR. Maternal infantfeeding style and children's adiposity at 5 years of age. Arch Pediatr Adolesc Med 2006; 160(5): 513-20.

[12] Gale CR, Javaid MK, Robinson SM, Law CM, Godfrey KM, Cooper C. Maternal size in pregnancy and body composition in children. J Clin Endocrinol Metab 2007; 92: 3904-11.

[13] Catalano PM, Farrell K, Thomas A, et al. Perinatal risk factors for childhood obesity and metabolic dysregulation. Am J Clin Nutr 2009; 90(5): 1303-13.

[14] Mingrone G, Manco M, Mora ME, et al. Influence of maternal obesity on insulin sensitivity and secretion in offspring. Diabetes Care 2008; 31(9): 1872-6.

[15] Getahun D, Ananth CV, Peltier MR, Salihu HM, Scorza WE. Changes in prepregnancy body mass index between the first and second pregnancies and risk of large-for-gestational-age birth. Am J Obstet Gynecol 2007; 196(6): 530.e1-8.

[16] Kral JG, Biron S, Simard S, et al. Large maternal weight loss from obesity surgery prevents transmission of obesity to children who were followed for 2 to 18 years. Pediatrics 2006; 118(6): e1644-9.

[17] Dabelea D, Hanson RL, Lindsay RS, et al. Intrauterine exposure to diabetes conveys risks for type 2 diabetes and obesity: a study of discordant sibships. Diabetes 2000; 49(11): 2208-11.

[18] Levin BE, Govek E. Gestational obesity accentuates obesity in obesity-prone progeny. Am J Physiol 1998; 275(4 Pt 2): R1374-9.

[19] Shankar K, Harrell A, Liu X, Gilchrist JM, Ronis MJ, Badger TM. Maternal obesity at conception programs obesity in the offspring. Am J Physiol Regul Integr Comp Physiol 2008; 294(2): R528-38.
White CL, Purpera MN, Morrison CD. Maternal obesity is necessary for programming effect of high-fat diet on offspring. Am J Physiol Regul Integr Comp Physiol 2009; 296(5): R1464-72.

Barker DJP. Mothers, babies, and disease in later life. 2nd ed. New York: Churchill Livingstone 1998.

Pedersen J. The pregnant diabetic and her newborn: problems and management. Baltimore, MD: Williams \& Wilkens 1967.

Whitaker RC, Dietz WH. Role of the prenatal environment in the development of obesity. J Pediatr 1998; 132: 768-76.

Catalano PM, Ehrenberg HM. The short- and long-term implications of maternal obesity on the mother and her offspring. BJOG 2006; 113(10): 1126-33.

Ramsay JE, Ferrell WR, Crawford L, Wallace AM, Greer IA, Sattar N. Maternal obesity is associated with dysregulation of metabolic, vascular, and inflammatory pathways. J Clin Endocrinol Metab 2002; 87(9): 4231-7.

[26] Yogev Y, Visser GH. Obesity, gestational diabetes and pregnancy outcome. Semin Fetal Neonatal Med 2009; 14(2): 77-84.

[27] Damm P. Future risk of diabetes in mother and child after gestational diabetes mellitus. Int J Gynaecol Obstet 2009; 104 Suppl 1: S25-6.

[28] Smith GN, Walker MC, Liu A, et al. A history of preeclampsia identifies women who have underlying cardiovascular risk factors. Am J Obstet Gynecol 2009; 200(1): 58.e1-8.

[29] Di Cianni G, Lencioni C, Volpe L, et al. C-reactive protein and metabolic syndrome in women with previous gestational diabetes. Diabetes Metab Res Rev 2007; 23(2): 135-40.

[30] Torloni MR, Betrán AP, Horta BL, et al. Prepregnancy BMI and the risk of gestational diabetes: a systematic review of the literature with meta-analysis. Obes Rev 2009; 10(2): 194-203.

[31] Silverman BL, Rizzo T, Green OC, et al. Long-term prospective evaluation of offspring of diabetic mothers. Diabetes 1991; 40 Suppl 2: 121-5.

[32] Gillman MW, Rifas-Shiman S, Berkey CS, Field AE, Colditz GA. Maternal gestational diabetes, birth weight, and adolescent obesity. Pediatrics 2003; 111(3): e221-6.

[33] Catalano PM, Thomas A, Huston-Presley L, Amini SB. Increased fetal adiposity: a very sensitive marker of abnormal in utero development. Am J Obstet Gynecol 2003;189(6):1698-704

[34] Yogev Y, Langer O, Xenakis EM, Rosenn B. The association between glucose challenge test, obesity and pregnancy outcome in 6390 non-diabetic women. J Matern Fetal Neonatal Med 2005; 17(1): 29-34

[35] Jensen DM, Korsholm L, Ovesen P, Beck-Nielsen H, MølstedPedersen L, Damm P. Adverse pregnancy outcome in women with mild glucose intolerance: is there a clinically meaningful threshold value for glucose? Acta Obstet Gynecol Scand 2008; 87(1): 59-62.

[36] The HAPO Study cooperative research group. Hyperglycemia and adverse pregnancy outcome (HAPO) study. Diabetes 2009; 58: 453-9.

[37] Vohr BR, McGarvey ST. Growth patterns of large-for-gestationalage and appropriate-for-gestational-age infants of gestational diabetic mothers and control mothers at age 1 year. Diabetes Care 1997; 20(7): 1066-72.

[38] Vohr BR, Boney CM. Gestational diabetes: the forerunner for the development of maternal and childhood obesity and metabolic syndrome? J Matern Fetal Neonatal Med 2008; 21(3): 149-57.

[39] Metzger BE. Long-term outcomes in mothers diagnosed with gestational diabetes mellitus and their offspring. Clin Obstet Gynecol 2007; 50(4): 972-9.

[40] Wright CS, Rifas-Shiman SL, Rich-Edwards JW, Taveras EM, Gillman MW, Oken E. Intrauterine exposure to gestational diabetes, child adiposity, and blood pressure. Am J Hypertens 2009; 22(2): 215-20.

[41] Group HSCR. Hyperglycemia and adverse pregnancy outcomes. N Engl J Med 2008; 358: 1991-2002.

[42] D'Anna R, Baviera G, Cannata ML, De Vivo A, Di Benedetto A, Corrado F. Midtrimester amniotic fluid leptin and insulin levels and subsequent gestational diabetes. Gynecol Obstet Invest 2007; 64(2): 65-8.

[43] Silverman BL, Rizzo TA, Cho NH, Metzger BE. Long-term effects of the intrauterine environment. The Northwestern University Diabetes in Pregnancy Center. Diabetes Care 1998; 21 Suppl 2: B142-9. 
[44] Bouret SG. Early life origins of obesity: Role of hypothalamic programming. J Pediatr Gastroenterol Nutr 2009; 48 Suppl 1: S318.

[45] Plagemann A. A matter of insulin: Developmental programming of body weight regulation. J Matern Fetal Neonatal Med 2008; 21(3): 143-8.

[46] Crowther CA, Hiller JE, Moss JR, et al. Effect of treatment of gestational diabetes mellitus on pregnancy outcomes. N Engl J Med 2005; 352(24): 2477-86.

[47] Uvena-Celebrezze J, Fung C, Thomas AJ, et al. Relationship of neonatal body composition to maternal glucose control in women with gestational diabetes mellitus. J Matern Fetal Neonatal Med 2002; 12(6): 396-401.

[48] Hillier TA, Pedula KL, Schmidt MM, Mullen JA, Charles MA, Pettitt DJ. Childhood obesity and metabolic imprinting: the ongoing effects of maternal hyperglycemia. Diabetes Care 2007; 30(9): 2287-92.

[49] Bevier WC, Fischer R, Jovanovic L. Treatment of women with an abnormal glucose challenge test (but a normal oral glucose tolerance test) decreases the prevalence of macrosomia. Am J Perinatol 1999; 16(6): 269-75.

[50] Sacks DA, Liu AI, Wolde-Tsadik G, Amini SB, Huston-Presley L, Catalano PM. What proportion of birth weight is attributable to maternal glucose among infants of diabetic women? Am J Obstet Gynecol 2006; 194(2): 501-7.

[51] Ricart W, López J, Mozas J, et al. Body mass index has a greater impact on pregnancy outcomes than gestational hyperglycaemia. Diabetologia 2005; 48(9): 1736-42.

[52] Bo S, Menato G, Signorile A, Bardelli C, et al. Obesity or diabetes: what is worse for the mother and for the baby? Diabetes Metab 2003; 29(2 Pt 1): 175-8.

[53] Miller RS, Thompson ML, Williams MA. Trimester-specific blood pressure levels in relation to maternal pre-pregnancy body mass index. Paediatr Perinat Epidemiol 2007; 21(6): 487-94.

[54] Bodnar LM, Ness RB, Markovic N, Roberts JM. The risk of preeclampsia rises with increasing prepregnancy body mass index. Ann Epidemiol 2005; 15(7): 475-82.

[55] Thadhani R, Stampfer MJ, Hunter DJ, Manson JE, Solomon GC, Curhan GC. High body mass index and hypercholesterolemia: Risk of hypertensive disorders of pregnancy. Obstet Gynecol 1999; 94: 543-50.

[56] Sibai BM, Ewell M, Levine RJ, et al. Risk factors associated with preeclampsia in healthy nulliparous women. The Calcium for Preeclampsia Prevention (CPEP) Study Group. Am J Obstet Gynecol 1997; 177(5): 1003-10.

[57] Xiong X, Demianczuk NN, Buekens P, Saunders LD. Association of preeclampsia with high birth weight for age. Am J Obstet Gynecol 2000; 183(1): 148-55.

[58] Stella CL, O'Brien JM, Forrester KJ, et al. The coexistence of gestational hypertension and diabetes: influence on pregnancy outcome. Am J Perinatol 2008; 25(6): 325-9.

[59] Herrera E, Amusquivar E, López-Soldado I, Ortega H. Maternal lipid metabolism and placental lipid transfer. Horm Res 2006; 65 (Suppl 3): 59-64.

[60] Wiznitzer A, Mayer A, Novack V, et al. Association of lipid levels during gestation with preeclampsia and gestational diabetes mellitus: a population-based study. Am J Obstet Gynecol 2009; 201(5): 482.el-8.

[61] Di Cianni G, Miccoli R, Volpe L, et al. Maternal triglyceride levels and newborn weight in pregnant women with normal glucose tolerance. Diabet Med 2005; 22(1): 21-5.

[62] Knopp RH, Magee MS, Walden CE, Bonet B, Benedetti TJ. Prediction of infant birth weight by GDM screening tests. Importance of plasma triglyceride. Diabetes Care 1992; 15(11): 1605-13.

[63] Nolan CJ, Riley SF, Sheedy MT, Walstab JE, Beischer NA. Maternal serum triglyceride, glucose tolerance, and neonatal birth weight ratio in pregnancy. Diabetes Care 1995; 18(12): 1550-6.

[64] Kitajima M, Oka S, Yasuhi I, Fukuda M, Rii Y, Ishimaru T. Maternal serum triglyceride at 24--32 weeks' gestation and newborn weight in nondiabetic women with positive diabetic screens. Obstet Gynecol 2001; 97(5 Pt 1): 776-80.

[65] Schaefer-Graf UM, Graf K, Kulbacka I, et al. Maternal lipids as strong determinants of fetal environment and growth in pregnancies with gestational diabetes mellitus. Diabetes Care 2008; 31(9): 1858-63.
[66] Visser M, Bouter LM, McQuillan GM, Wener MH, Harris TB. Low-grade systemic inflammation in overweight children. Pediatrics 2001; 107(1): E13.

[67] Visser M, Bouter LM, McQuillan GM, Wener MH, Harris TB. Elevated C-reactive protein levels in overweight and obese adults. JAMA 1999; 282(22): 2131-5.

[68] Ridker PM, Hennekens CH, Buring JE, Rifai N. C-reactive protein and other markers of inflammation in the prediction of cardiovascular disease in women. N Engl J Med 2000; 342(12): 836-43.

[69] Pradhan AD, Manson JE, Rifai N, Buring JE, Ridker PM. Creactive protein, interleukin 6 , and risk of developing type 2 diabetes mellitus. JAMA 2001; 286(3): 327-34.

[70] Retnakaran R, Hanley AJ, Raif N, Connelly PW, Sermer M, Zinman B. C-reactive protein and gestational diabetes: the central role of maternal obesity. J Clin Endocrinol Metab 2003; 88(8): $3507-12$.

[71] Wolf M, Sandler L, Hsu K, Vossen-Smirnakis K, Ecker JL, Thadhani R. First-trimester C-reactive protein and subsequent gestational diabetes. Diabetes Care 2003; 26(3): 819-24.

[72] Tjoa ML, van Vugt JM, Go AT, Blankenstein MA, Oudejans CB, van Wijk IJ. Elevated C-reactive protein levels during first trimester of pregnancy are indicative of preeclampsia and intrauterine growth restriction. J Reprod Immunol 2003; 59(1): 2937.

[73] Qiu C, Sorensen TK, Luthy DA, Williams MA. A prospective study of maternal serum C-reactive protein (CRP) concentrations and risk of gestational diabetes mellitus. Paediatr Perinat Epidemiol 2004; 18(5): 377-84.

[74] Dahlgren J, Nilsson C, Jennische E, et al. Prenatal cytokine exposure results in obesity and gender-specific programming. Am J Physiol Endocrinol Metab 2001; 281(2): E326-34

[75] Radaelli T, Uvena-Celebrezze J, Minium J, Huston-Presley L, Catalano P, Hauguel-de Mouzon S. Maternal interleukin-6: marker of fetal growth and adiposity. J Soc Gynecol Investig 2006; 13(1): 53-7.

[76] Aaltonen R, Heikkinen T, Hakala K, Laine K, Alanen A. Transfer of proinflammatory cytokines across term placenta. Obstet Gynecol 2005; 106(4): 802-7.

[77] Zaretsky MV, Alexander JM, Byrd W, Bawdon RE. Transfer of inflammatory cytokines across the placenta. Obstet Gynecol 2004; 103(3): 546-50.

[78] Catalano PM, Presley L, Minium J, Hauguel-de Mouzon S. Fetuses of obese mothers develop insulin resistance in utero. Diabetes Care 2009; 32(6): 1076-80.

[79] Nelson SM, Sattar N, Freeman DJ, Walker JD, Lindsay RS Inflammation and endothelial activation is evident at birth in offspring of mothers with type 1 diabetes. Diabetes 2007; 56(11): 2697-704.

[80] Yogev Y, Langer O, Brustman L, Rosenn B. Pre-eclampsia and gestational diabetes mellitus: does a correlation exist early in pregnancy? J Matern Fetal Neonatal Med 2004; 15(1): 39-43.

[81] Lykke JA, Langhoff-Roos J, Sibai BM, Funai EF, Triche EW, Paidas MJ. Hypertensive pregnancy disorders and subsequent cardiovascular morbidity and type 2 diabetes mellitus in the mother. Hypertension 2009; 53(6): 944-51.

[82] Colatrella A, Braucci S, Festa C, et al. Hypertensive Disorders in Normal/Over-weight and Obese Type 2 Diabetic Pregnant Women. Exp Clin Endocrinol Diabetes 2009; 117(8): 373-7.

[83] Joffe GM, Esterlitz JR, Levine RJ, et al. The relationship between abnormal glucose tolerance and hypertensive disorders of pregnancy in healthy nulliparous women. Calcium for Preeclampsia Prevention (CPEP) Study Group. Am J Obstet Gynecol 1998; 179(4): 1032-7.

[84] Fasting MH, Oken E, Mantzoros CS, et al. Maternal levels of corticotropin-releasing hormone during pregnancy in relation to adiponectin and leptin in early childhood. J Clin Endocrinol Metab 2009; 94(4): 1409-15.

[85] Andres R. The effect of obesity on total mortality. Int J Obes (Lond) 1980; 4: 381-6.

[86] Ruderman LB, Berchtold P, Schneider S. Obesity-associated disorders in normal-weight individuals: Some speculations. Int $\mathrm{J}$ Obes (Lond) 1982; 6 Suppl 1: 151-7.

[87] Sims EAH. Characterization of the syndromes of obesity. In: Brodoff BN, Bleicher SJ, eds. Diabetes Mellitus and Obesity. Baltimore: Williams \& Wilkins 1982: 219-26. 
[88] Conus F, Rabasa-Lhoret R, Péronnet F. Characteristics of metabolically obese normal-weight (MONW) subjects. Appl Physiol Nutr Metab 2007; 32(1): 4-12.

[89] Karelis AD, Brochu M, Rabasa-Lhoret R. Can we identify metabolically healthy but obese individuals (MHO)? Diabetes Metab 2004; 30(6): 569-72.

[90] Sims EAH. Are there persons who are obese, but metabolically healthy? Metabolism 2001; 50(12): 1499-504.

[91] Ruderman N, Chisholm D, Pi-Sunyer X, Schneider S. The metabolically obese, normal-weight individual revisited. Diabetes 1998; 47: 699-713.

[92] Bonora E, Kiechl J, Willeit J, et al. Prevalence of insulin resistance in metabolic disorders: the Bruneck Study. Diabetes 1998; 47(10): 1643-9.

[93] Muscelli E, Camastra S, Gastaldelli A, et al. Influence of duration of obesity on the insulin resistance of obese non-diabetic patients. Int J Obes Relat Metab Disord 1998; 22(3): 262-7.

[94] Brochu M, Tchernof A, Dionne IJ, et al. What are the physical characteristics associated with a normal metabolic profile despite a high level of obesity in postmenopausal women? J Clin Endocrinol Metab 2001; 86(3): 1020-5.

[95] Pouliot MC, Després JP, Lemieux S, et al. Waist circumference and abdominal sagittal diameter: best simple anthropometric indexes of abdominal visceral adipose tissue accumulation and related cardiovascular risk in men and women. Am J Cardiol 1994; 73(7): 460-8.

[96] Sattar N, Clark P, Holmes A, Lean ME, Walker I, Greer IA. Antenatal waist circumference and hypertension risk. Obstet Gynecol 2001; 97(2): 268-71.
[97] Branchtein L, Schmidt MI, Mengue SS, Reichelt AJ, Matos MC, Duncan BB. Waist circumference and waist-to-hip ratio are related to gestational glucose tolerance. Diabetes Care 1997; 20(4): 50911.

[98] Bitó T, Földesi I, Nyári T, Pál A. Prediction of gestational diabetes mellitus in a high-risk group by insulin measurement in early pregnancy. Diabet Med 2005; 22(10): 1434-9.

[99] Poon LC, Kametas NA, Chelemen T, Leal A, Nicolaides KH. Maternal risk factors for hypertensive disorders in pregnancy: a multivariate approach. J Hum Hypertens 2010; 24(2): 104-10.

[100] Kim C, Liu T, Valdez R, Beckles GL. Does frank diabetes in firstdegree relatives of a pregnant woman affect the likelihood of her developing gestational diabetes mellitus or nongestational diabetes? Am J Obstet Gynecol 2009; 201(6): 576.e1-6.

[101] Tabák AG, Tamás G, Péterfalvi A, et al. The effect of paternal and maternal history of diabetes mellitus on the development of gestational diabetes mellitus. J Matern Fetal Neonatal Med 2009; 32(7): 606-10.

[102] Lu GC, Luchesse A, Chapman V, Cliver S, Rouse DJ. Screening for gestational diabetes mellitus in the subsequent pregnancy: is it worthwhile? Am J Obstet Gynecol 2002; 187(4): 918-21.

[103] Villamor E, Cnattingius S. Interpregnancy weight change and risk of adverse pregnancy outcomes: a population-based study. Lancet 2006; 368(9542): 1164-70.

[104] Levy A, Wiznitzer A, Holcberg G, Mazor M, Sheiner E. Family history of diabetes mellitus as an independent risk factor for macrosomia and cesarean delivery. J Matern Fetal Neonatal Med $2010 ; 32(2): 148-52$.

(C) Chandler-Laney and Bush; Licensee Bentham Open.

This is an open access article licensed under the terms of the Creative Commons Attribution Non-Commercial License (http: //creativecommons.org/licenses/by$\mathrm{nc} / 3.0 /$ ), which permits unrestricted, non-commercial use, distribution and reproduction in any medium, provided the work is properly cited. 